\title{
CUSTO DE PRODUÇÃO E INDICADORES DE RENTABILIDADE DA CULTURA DO MILHO SAFRINHA ${ }^{1}$
}

\author{
Fernanda de Paiva Badiz Furlaneto ${ }^{2}$, Maura Seiko Tsutsui Esperancini ${ }^{3}$
}

\section{ABSTRACT \\ PRODUCTION COST AND PROFITABILITY OF SECOND SEASON CORN CROP}

The objective of this study was to evaluate the production cost and profitability of the second season corn crop in the Médio Paranapanema region, São Paulo State, Brazil, under two technological levels (middle and high technology), crop 2008/2009, and compare the results with the 2006/2007 agricultural year. Effective and total operational cost as well as five profitability indicators were used. It was concluded that the high technology production cost for corn crop (direct seedling, sowing during the recommended period, use of simple hybrid seed, application of side-dressing fertilization, and treatment of seeds with different insecticides) was superior to the middle technology production cost (direct seedling, sowing after the recommended time, use of double hybrid seed, and no side-dressing fertilization). However, the average cost was inferior (US\$ 8.5), due to a higher yield (4t). The high technology corn crop was profitable (gross income and profitability index of $14 \%$ and $12 \%$, respectively). For the middle technology crop, profitability indexes pointed out that the cropping system needs to be reevaluated by technicians and research institutions, regarding the adequate technical recommendations. Profitability indexes decreased considerably in both cropping systems. It was verified that, in relation to the 2006/2007 harvest period, the total operational cost increased for both technologies, mainly because of the increase of supplies prices.

KEY-WORDS: Zea mays; second corn crop; economic return; technological level; profitability.

\section{INTRODUÇÃO}

A extensão territorial e a diversidade climática no Brasil tornam possível o cultivo de milho em, praticamente, todas as épocas do ano. Na safra de verão, a competição com a cultura da soja e a expansão do sistema plantio direto na palha provocaram a substituição de parte do cultivo com milho, que passou

\section{RESUMO}

Objetivou-se estimar o custo de produção e a rentabilidade do milho safrinha, em dois níveis tecnológicos (alta e média tecnologias), safra 2008/2009, e comparar os resultados com os do ano agrícola 2006/2007, na região do Médio Paranapanema, Estado de São Paulo. Foram utilizadas estruturas do custo operacional efetivo e total e cinco indicadores de rentabilidade. Concluiu-se que o custo de produção do milho cultivado com alta tecnologia (plantio direto, semeadura no período recomendado, uso de semente de híbrido simples, aplicação de adubação em cobertura e tratamento de semente com inseticidas diferenciados) foi superior ao do plantio com média tecnologia (plantio direto, semeadura após a época recomendada, uso de semente de híbrido duplo e sem adubação de cobertura). Porém, o custo médio da produção com alta tecnologia $(\mathrm{R} \$ 18,4)$ foi menor, em função da maior produtividade por área (4 t). Os indicadores de rentabilidade mostraram-se favoráveis ao cultivo com alta tecnologia (margem bruta e índice de lucratividade de $14 \%$ e $12 \%$, respectivamente). No cultivo com média tecnologia, os índices de lucratividade apontaram que o sistema produtivo precisa ser reavaliado por técnicos e instituições de pesquisa, para fins de recomendação técnica adequada. Verificou-se que, em relação à safra 2006/2007, houve aumento no custo operacional total, nas duas tecnologias, devido, principalmente, ao aumento do preço dos insumos.

PALAVRAS-CHAVE: Zea mays; segunda safra; retorno econômico; nível tecnológico; lucratividade.

a ser realizado em sucessão à oleaginosa, como segunda safra ou safrinha (Coelho 2005, Tsunechiro \& Ferreira 2008).

A produção do milho safrinha, safra 2009/2010, na região Sudeste do Brasil, respondeu por $21 \%$ da produção nacional. Deste total, a produção do Estado de São Paulo representou 39\%. A região paulista do Médio Paranapanema é a principal produtora do Es-

1. Trabalho recebido em jan./2010 e aceito para publicação em ago./2010 ( ${ }^{\circ}$ registro: PAT 8609/ DOI: 10.5216/pat.v40i3.8609).

2. Agência Paulista de Tecnologia dos Agronegócios (APTA), Unidade de Pesquisa e Desenvolvimento, Marília, SP, Brasil.

E-mail: fernandafurlaneto@apta.sp.gov.br.

3. Universidade Estadual Paulista, Campus Botucatu, Departamento de Gestão e Tecnologia Agroindustrial, Botucatu, SP, Brasil.

E-mail:maura@fca.unesp.br. 
tado e é reconhecida pelo desenvolvimento de novas tecnologias de produção (Duarte 2004).

Atualmente, no Médio Paranapanema, predomina o sistema plantio direto ( $80 \%$ da área), sendo a rotação de culturas pouco praticada. Em muitas lavouras, emprega-se a sucessão soja e milho safrinha, sem interrupção, há mais de quinze anos (Cimonetti 2005).

O agronegócio do milho apresenta projeções de mercado favoráveis, em decorrência da demanda deste cereal para abastecer as cadeias de carnes de frango e suíno de outros países, servir de matériaprima para a produção de combustíveis alternativos e minimizar os efeitos da escassez de trigo no mundo. Porém, a cultura do milho ainda requer investimentos em produtividade, para se tornar sustentável ao longo dos anos, e tem a infraestrutura como grave obstáculo à sua expansão (Barros 2008).

Dada a relevância econômica desta atividade, na região paulista do Médio Paranapanema, objetivou-se estimar o custo de produção e os indicadores de rentabilidade da cultura do milho safrinha, safra 2008/2009, em dois níveis de tecnologia, e comparálos com os obtidos no ano agrícola 2006/2007.

\section{MATERIAL E MÉTODOS}

No Médio Paranapanema, o milho safrinha é semeado até o dia vinte de março. Predominam, no mercado de sementes, os híbridos simples (45\%), semeados no início da época recomendada para o plantio; híbridos triplos (35\%); híbridos duplos $(10 \%)$; e variedades $(10 \%)$, sendo que os dois últimos são cultivados no final da época recomendada. Os materiais precoces são os preferidos pelos produtores, ao passo que os superprecoces são pouco utilizados regionalmente, devido ao menor potencial produtivo e às condições edafoclimáticas locais (Carvalho 2007).

Pesquisas recentes, realizadas pelo IAC/APTA/ CATI/EMPRESAS, concluíram que os híbridos simples e triplos de milho mais adaptados à região do Médio Paranapanema são o 30F35, DKB 390, AG 8088, 2B587, AS 1570, AS 1567, Impacto, 2B710, Maximus, AG 8060 e Somma. Já os híbridos duplos e variedades que mais se destacaram, quanto à produtividade, foram o AG 1051, DKB 350, DKB 747, SG 6418, AG 2040 e IAC 8333 (Duarte 2008).

A diferenciação do sistema de produção, no Médio Paranapanema, refere-se à época de seme- adura, tipo de semente, adubo e inseticida utilizado na cultura. Em síntese, na região estudada, foram consideradas as seguintes características dos sistemas de produção de milho safrinha: 1) sistema de alta tecnologia, com produtividade esperada de $4.000 \mathrm{~kg} \mathrm{ha}^{-1}$, plantio direto, semeadura no período recomendado (até 20 de março), uso de semente de híbrido simples, adubação de cobertura e tratamento de semente com inseticidas diferenciados; e 2) sistema de média tecnologia, com produtividade esperada de $3.000 \mathrm{~kg} \mathrm{ha}^{-1}$, plantio direto, semeadura após a época recomendada (entre 20 e 30 de março) e uso de semente de híbrido duplo, sem adubação de cobertura. A operação de colheita foi terceirizada, nos dois sistemas produtivos.

A metodologia do cálculo de custo de produção utilizada foi a descrita por Matsunaga et al. (1976). As estruturas consideradas no sistema produtivo foram o custo operacional efetivo (COE), que envolve as despesas efetuadas com mão de obra, operações de máquinas/equipamentos e materiais consumidos ao longo do processo produtivo, e o custo operacional total (COT), que é o custo operacional efetivo, acrescido dos gastos com encargos sociais diretos, contribuição de seguridade social rural, encargos financeiros, assistência técnica e depreciação de máquinas.

Os indicadores de análise de resultados de rentabilidade utilizados no trabalho foram os definidos por Martin et al. (1998): a) Receita Bruta (RB): receita esperada para determinada produção por hectare, para um preço de venda pré-definido ou efetivamente recebido, ou seja, $R B=\operatorname{Pr} \times P u$, onde $P r=$ produção da atividade por unidade de área e $P u=$ preço unitário do produto (o preço médio do milho recebido pelo produtor correspondeu a $\mathrm{R} \$ 21,00 / \mathrm{sc}$. e o preço médio de atacado foi de $\mathrm{R} \$ 23,50 / \mathrm{sc}$. No presente trabalho, analisou-se o custo e a rentabilidade do produtor levando-se em consideração o custo por saca equivalente a R \$ 21,00/sc.); b) Lucro Operacional (LO) ou receita líquida $(\mathrm{RL})$ : diferença entre a receita bruta e o custo operacional por hectare $(L O=R B-C O T$, onde $C O T=$ custo operacional total de produção); c) Margem Bruta (MB): margem, em relação ao custo operacional, considerando-se o preço unitário de venda e a produtividade do sistema de produção, sendo $M B=$ (RB - COT)/ COT x 100; d) Índice de Lucratividade (IL): relação entre o lucro operacional e a receita bruta, em percentagem, onde $I L=(L O / R B) \times 100$; e) Ponto de Nivelamento $(\mathrm{PN})$ : indicador de custo, em relação à unidade do produto, sendo $P N=C O T / P u$. 
As matrizes de coeficientes técnicos de produção foram elaboradas com base em informações coletadas em dezembro de 2009, junto a técnicos da Cooperativa dos Cafeicultores da Média Sorocabana (Coopermota), Cooperativa Agropecuária de Pedrinhas Paulista (CAP) e Coordenadoria de Assistência Técnica e Extensão Rural (Cati), além de produtores rurais representativos no uso das tecnologias descritas na região do Médio Paranapanema. Foram aplicados questionários semiestruturados, nos municípios de Assis, Palmital, Cândido Mota e Pedrinhas Paulista.

Os preços dos materiais, mão de obra e serviços foram obtidos nas cidades de Assis, Cândido Mota e Pedrinhas Paulista. O preço médio do milho safrinha recebido pelo produtor, na safra 2008/2009, foi estimado em R $\$ 21,00$ por saca de $60 \mathrm{~kg}$. A cotação do dólar comercial, no período, era de $\mathrm{R} \$ 2,17$.
Para a comparação da participação dos itens do custo operacional, bem como dos indicadores de rentabilidade, com a safra 2006/2007, utilizaram-se os dados disponibilizados por Tsunechiro et al. (2006).

\section{RESULTADOS E DISCUSSÃO}

Os coeficientes técnicos da cultura do milho safrinha, explorado com média e alta tecnologias, foram iguais, nas operações que compreendem o tratamento de semente, dessecação, aplicação de formicida, semeadura/adubação e aplicação de herbicida pós-emergente/inseticida. Os sistemas diferenciaram-se nos itens adubação de cobertura e transporte de insumos/materiais. As operações e materiais consumidos encontram-se detalhados nas Tabelas 1 e 2 .

Tabela 1. Coeficientes técnicos de produção do milho safrinha, por hectare, em sistema plantio direto, utilizando-se média tecnologia (3.000 kg ha-1) (Médio Paranapanema, SP, safra 2008/2009).

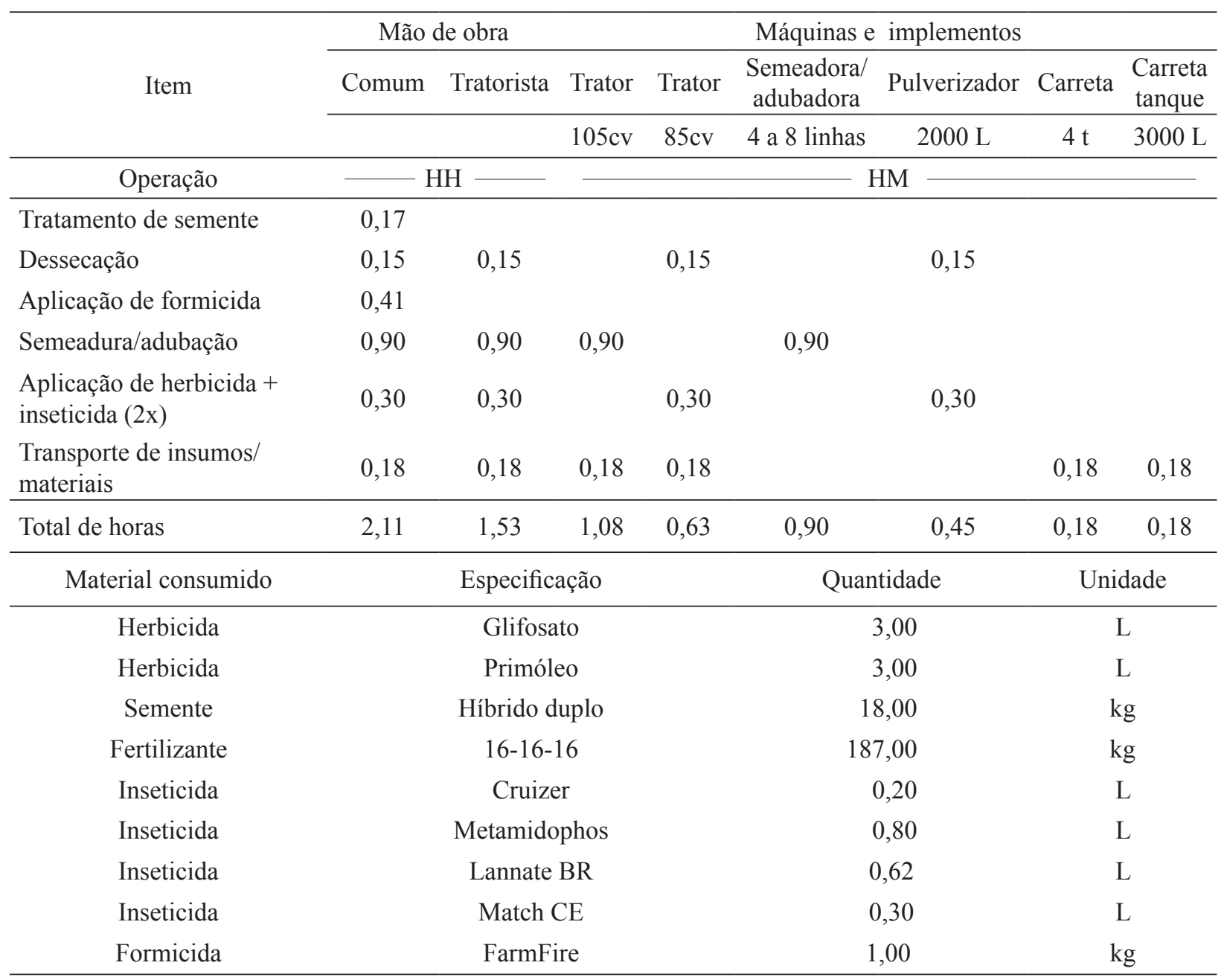


Tabela 2. Coeficientes técnicos de produção do milho safrinha, por hectare, em sistema plantio direto, utilizando-se alta tecnologia ( $4.000 \mathrm{~kg} \mathrm{ha}^{-1}$ ) (Médio Paranapanema, SP, safra 2008/2009).

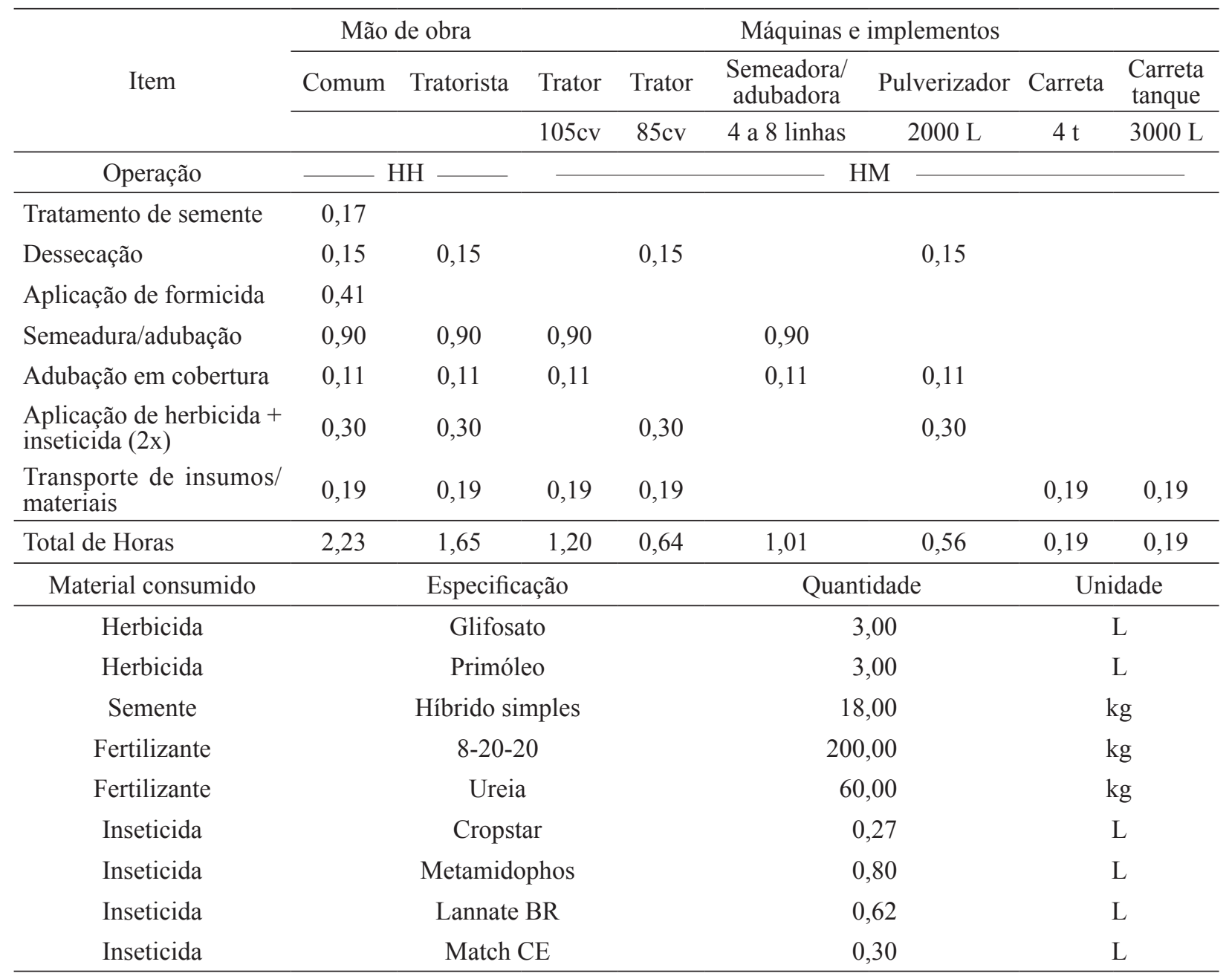

Segundo Duarte (2004), as diferenças tecnológicas de manejo adotadas pelos agricultores de milho safrinha, na região do Médio Paranapanema (SP), decorrem, principalmente, da época de plantio, pois procura-se minimizar as perdas econômicas, devido às adversidades climáticas que ocorrem, com maior frequência, quando a semeadura é realizada após o período recomendado. Neste caso, opta-se pela utilização de sementes com qualidade genética inferior e redução dos dispêndios com insumos, fazendo com que os investimentos em tecnologia de produção sejam inversamente proporcionais aos níveis de risco.

O custo operacional total (COT) de produção, para o milho de alta tecnologia, foi de $\mathrm{R} \$ 1.223,8$ (US\$ 564,0) por hectare, ou seja, R\$ 18,4 (US\$ 8,5) por saca de $60 \mathrm{~kg}$. O milho de média tecnologia teve
COT de R $\$ 1.047,1$ (US\$ 482,5) por hectare e de R\$ 20,9 (US\$ 9,6) por saca de $60 \mathrm{~kg}$.

A distribuição dos itens do custo de produção, do milho que utiliza alta tecnologia, é semelhante à dos de média tecnologia. O diferencial encontra-se no maior valor relativo destes fatores, que elevam o valor do custo operacional efetivo (COE) para $\mathrm{R} \$ 1.105,6$ (US\$ 509,4) por hectare, com participação de 73\% para adubos, agrotóxicos e sementes.

O valor da semente (18\% do COE) foi elevado, devido ao alto potencial genético de produção, justificando a maior aplicação de adubo na semeadura e a cobertura com nitrogênio, fazendo com que o preço relativo do item "fertilizante" tivesse maior participação no COT. Os herbicidas têm emprego idêntico, nos dois sistemas de produção, com participação percentual menor na produção com alta tecnologia. 
No cultivo do milho safrinha com média tecnologia, o COE foi de R $\$ 947,8$ por hectare (US\$ 436,7). Observou-se que, em decorrência de as operações serem mecanizadas, o item "mão de obra" onerou este custo, em $1 \%$ do COT. Os itens mais representativos foram "adubos", "agrotóxicos" e "sementes", representando 70\% do COE, mesmo considerando-se que as sementes utilizadas são de menor potencial produtivo e a adubação realizada apenas na semeadura. As participações dos gastos com defensivos atingiram $23 \%$ do COE.

Richetti (2007) destaca que os insumos também constituem a maior parte do custo de produção do milho safrinha cultivado no Mato Grosso do Sul e Mato Grosso. Portanto, os agricultores devem ficar atentos às recomendações técnicas, visando à otimização dos produtos agrícolas, principalmente os fertilizantes.

Os demais custos, excluindo-se os itens do COE, responderam por $9 \%$ do COT, nos sistemas avaliados. Em relação ao COT, a parcela referente aos encargos financeiros, contribuição de seguridade social e depreciação de máquinas foram os itens que mais oneraram os custos indiretos.

Comparando-se os dois sistemas, notou-se que o COT foi $14 \%$ superior no sistema de alta tecnologia, embora o custo unitário tenha sido $12 \%$ inferior, devido à produtividade. Estes valores são semelhantes aos encontrados por Oliveira et al. (2007) (Tabela $3 \mathrm{e}$ Figura 1).

Os indicadores de rentabilidade, para o milho safrinha, mostraram-se favoráveis ao cultivo com alta tecnologia. A margem bruta apresentou valor de 14\% e índice de lucratividade de $12 \%$. No milho de média tecnologia, os indicadores de rentabilidade apontaram que este sistema produtivo precisa ser reavaliado por técnicos, instituições de pesquisa e empresas privadas, para fins de recomendação técnica adequada. Identificou-se que a margem bruta $(0,3 \%)$, o índice de lucratividade $(0,2 \%)$ e o ponto de nivelamento (49,9 sacas por hectare) foram desfavoráveis para a atividade (Tabela 4).

Analisando-se os dados do COT obtidos por Tsunechiro et al. (2006), verificou-se que houve aumento percentual no COE de $64 \%$ e $49 \%$, no COT de $61 \%$ e $47 \%$ e no custo operacional por unidade de $60 \%$ e $47 \%$, em 2008/2009, em relação ao ano agrícola 2006/2007, nos sistemas de média e alta tecnologia, respectivamente.
Tabela 3. Estimativa do custo operacional (em R $\$$ de dezembro de 2009) do milho safrinha, por hectare, em sistema plantio direto, com emprego de média e alta tecnologia (Médio Paranapanema, SP, safra 2008/2009).

\begin{tabular}{|c|c|c|c|c|}
\hline \multirow[t]{2}{*}{ Item } & \multicolumn{2}{|c|}{$\begin{array}{l}\text { Média tecnologia } \\
\left(3.000 \mathrm{~kg} \mathrm{ha}^{-1}\right)\end{array}$} & \multicolumn{2}{|c|}{$\begin{array}{l}\text { Alta tecnologia } \\
\left(4.000 \mathrm{~kg} \mathrm{ha}^{-1}\right)\end{array}$} \\
\hline & $\mathrm{R} \$$ & $\% \mathrm{COT}$ & $\mathrm{R} \$$ & $\% \mathrm{COT}$ \\
\hline Mão de obra & 13,1 & 1,3 & 17,1 & 1,4 \\
\hline Sementes & 144 & 13,8 & 198 & 16,2 \\
\hline Fertilizantes & 383,4 & 36,6 & 500,0 & 40,9 \\
\hline Herbicidas & 77,7 & 8,2 & 77,7 & 7,0 \\
\hline Inseticidas & 139,0 & 13,3 & 104,9 & 8,6 \\
\hline Operações de máquinas & 72,4 & 6,9 & 79,7 & 6,5 \\
\hline Empreita $^{1}$ & 118,2 & 11,3 & 128,2 & 10,5 \\
\hline $\begin{array}{l}\text { Custo operacional } \\
\text { efetivo (COE) }\end{array}$ & 947,8 & 90,5 & $1.105,60$ & 90,3 \\
\hline Depreciação de máquinas & 24,2 & 2,3 & 26,0 & 2,1 \\
\hline Encargos sociais diretos ${ }^{2}$ & 4,3 & 0,4 & 5,7 & 0,5 \\
\hline $\mathrm{CESSR}^{3}$ & 24,2 & 2,3 & 32,2 & 2,6 \\
\hline Assistência técnica ${ }^{4}$ & 19,0 & 1,8 & 22,1 & 1,8 \\
\hline Encargos financeiros $^{5}$ & 27,6 & 2,6 & 32,2 & 2,6 \\
\hline $\begin{array}{l}\text { Custo operacional total } \\
(\mathrm{COT})\end{array}$ & $1.047,10$ & 100 & $1.223,80$ & 100 \\
\hline $\begin{array}{l}\text { Custo operacional por } \\
\text { unidade }(\mathrm{R} \$ / \mathrm{sc})\end{array}$ & 20,9 & - & 18,4 & - \\
\hline $\begin{array}{l}\text { Custo operacional por } \\
\text { unidade (US } \$ / \text { ha })^{6}\end{array}$ & 9,6 & - & 8,5 & - \\
\hline
\end{tabular}

${ }^{1}$ Colheita (4,2 sacas) e transporte ( $\mathrm{R} \$ 0,6 /$ saca) do produto.

${ }^{2}$ Mão de obra comum e tratorista.

${ }^{3}$ Contribuição de seguridade social de $2,3 \%$, sobre a receita bruta.

${ }^{4} 2 \%$ do COE.

${ }^{5}$ Taxa de juros de $8,7 \%$ a. a., sobre $50 \%$ do COE, durante o ciclo de produção. ${ }^{6} \mathrm{US} \$=\mathrm{R} \$ 2,17$.

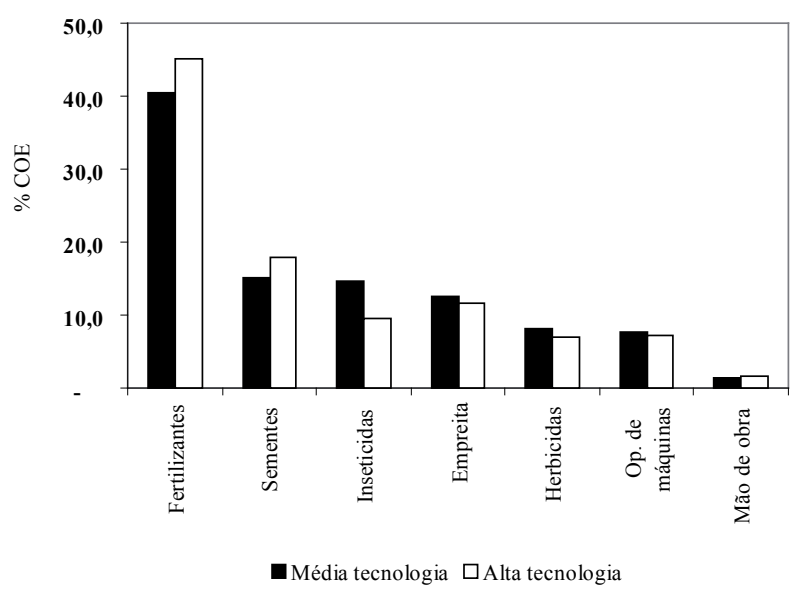

Figura 1. Composição relativa dos itens do custo operacional efetivo (COE) do milho safrinha, por hectare, em sistema plantio direto, com emprego de média e alta tecnologia (Médio Paranapanema, SP, safra 2008/2009).

Quanto aos índices de lucratividade, observouse decréscimo na rentabilidade do agricultor, principalmente em relação ao cultivo do milho safrinha com média tecnologia. A redução média da receita bruta foi de $30 \%$. Já os valores do lucro operacional, 
Tabela 4. Indicadores de rentabilidade para o milho safrinha, por hectare, em sistema plantio direto, com emprego de média e alta tecnologia (Médio Paranapanema, SP, safra 2008/2009).

\begin{tabular}{lccc}
\hline \multicolumn{1}{c}{ Indicador } & Unidade & $\begin{array}{c}\text { Média tecnologia } \\
\left(3.000 \mathrm{~kg} \mathrm{ha}^{-1}\right)\end{array}$ & $\begin{array}{c}\text { Alta tecnologia } \\
\left(4.000 \mathrm{~kg} \mathrm{ha}^{-1}\right)\end{array}$ \\
\hline Receita bruta (RB) & $\mathrm{R} \$ / \mathrm{ha}^{*}$ & $1.050,0$ & $1.400,7$ \\
Lucro operacional (LO) & $\mathrm{R} \$ / \mathrm{ha}$ & 2,9 & 176,9 \\
Margem bruta (MB) & $\%$ & 0,3 & 14,5 \\
Índice de lucratividade (IL) & $\%$ & 0,2 & 12,6 \\
Ponto de nivelamento (PN) & $\mathrm{sc} / \mathrm{ha}$ & 49,9 & 58,3 \\
\hline
\end{tabular}

* Preço de venda: $\mathrm{R} \$ 21,0 / \mathrm{sc} .60 \mathrm{~kg}$.

margem bruta e índice de lucratividade reduziramse, aproximadamente, 98\%, no sistema de média tecnologia, e $39 \%$, no de alta tecnologia. O ponto de nivelamento aumentou $22 \%$ e $12 \%$, nos sistemas de média e alta tecnologia, respectivamente. O preço de venda por saca de $60 \mathrm{~kg}$, no ano de 2008, subiu $31 \%$, em relação à safra anterior (Figura 2).

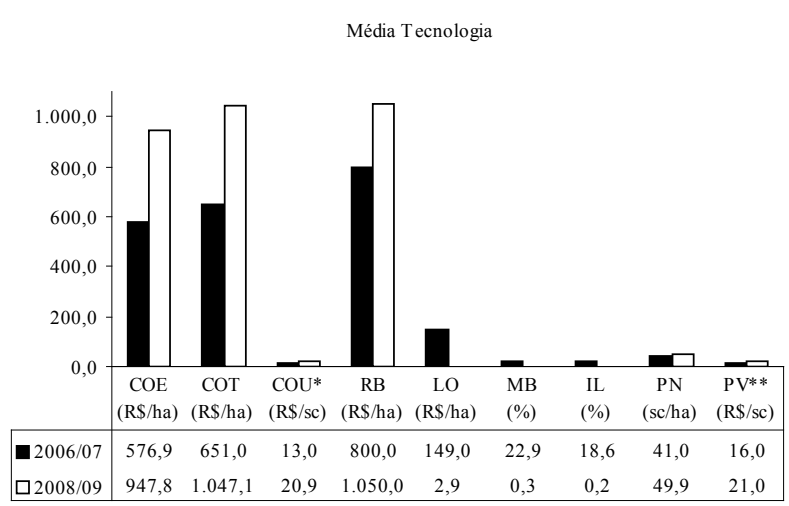

Alta Tecnologia

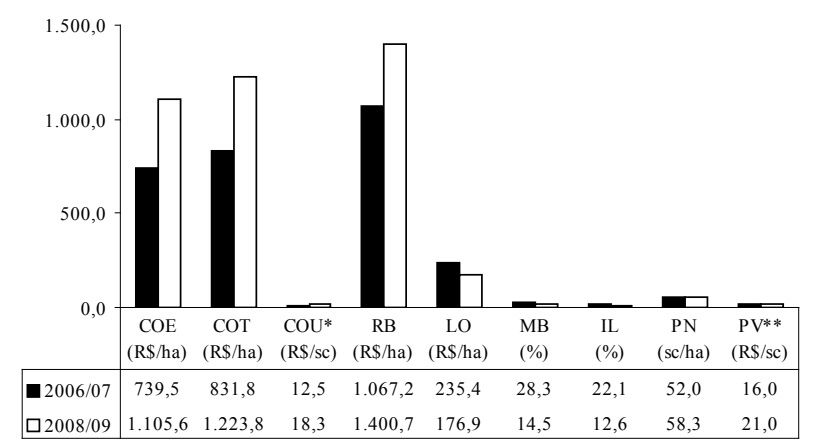

Figura 2. Comparação entre o custo de produção e os indicadores de rentabilidade para o milho safrinha, por hectare, em sistema plantio direto, com emprego de média e alta tecnologia (Médio Paranapanema, SP, safra 2008/2009). * Custo operacional por unidade; ** Preço de venda.
A redução da rentabilidade do milho safrinha, no decorrer dos anos, também foi descrita por Sallit \& Toledo (1990), Souza et al. (1993), Esperancini et al. (2006) e Tsunechiro et al. (2006). Estes autores ressaltaram, no entanto, que os produtores rurais do Médio Paranapanema têm buscado se adaptar às condições de mercado e às limitações ambientais inerentes à produção do milho safrinha. Porém, existe a necessidade de um gerenciamento eficiente dos custos de produção, em decorrência da tendência de redução crescente no índice de lucratividade da atividade.

\section{CONCLUSÕES}

1. O custo operacional total do milho safrinha cultivado com alta tecnologia foi superior ao do plantio com média tecnologia. Porém, o custo unitário, no primeiro sistema, foi inferior, devido à maior produção por unidade de área. O item "fertilizantes" foi o fator mais representativo no COT, nos dois sistemas produtivos.

2. Os indicadores de rentabilidade apontaram que o milho safrinha cultivado com alta tecnologia foi lucrativo. A produção com média tecnologia precisa ser readequada pelo segmento setorial, em decorrência do aumento no preço dos insumos, nos últimos anos.

3. A comparação do custo de produção do ano 2006/2007, em relação a 2008/2009, mostrou que houve aumento no custo operacional total, nas tecnologias analisadas na pesquisa. Já os índices de lucratividade decresceram, consideravelmente, nos dois sistemas de produção.

\section{REFERÊNCIAS}

BARROS, F. R. T. Mercado \& perspectivas: milho. In: ANUÁRIO da agricultura brasileira. São Paulo: Agra FNP Pesquisas Ltda., 2008. p. 397-398.

CARVALHO, S. A. L. Sistemas de produção de milho safrinha no Médio Vale Paranapanema. In: SEMINÁRIO NACIONAL DE MILHO SAFRINHA, 9., 2007, Dourados. Anais... Dourados: Embrapa Agropecuária Oeste, 2007. p. 71-75.

CIMONETTI, D. Sistemas de produção de milho safrinha no Médio Vale Paranapanema. In: SEMINÁRIO NACIONAL DE MILHO SAFRINHA, 8., 2005, Assis. Anais... Campinas: IAC, 2005. p. 65-73. 
COELHO, A. M. O potássio na cultura do milho. In: SIMPÓSIO SOBRE POTÁSSIO NA AGRICULTURA BRASILEIRA, 2., 2005, Piracicaba. Anais... Piracicaba: Associação Brasileira para Pesquisa da Potassa e do Fosfato, 2005. p. 610-658.

DUARTE, A. P. Avaliação de milho safrinha na região do Médio Vale Paranapanema. In: DUARTE, A. P. et al. (Coords.). Avaliação regional de cultivares de milho no Estado de São Paulo: resultados 2007/2008. Assis: IAC, 2008. p. 6-15.

DUARTE, A. P. Milho safrinha: características e sistemas de produção. In: GALVÃO, V. C. C.; MIRANDA, G. V. (Eds.). Tecnologia da produção de milho. Viçosa: UFV, 2004. p. $109-138$

ESPERANCINI, M. S. T. et al. Retorno e risco em sistemas de sucessão de soja no Estado de São Paulo, 2005. In: CONGRESSO DA SOCIEDADE BRASILEIRA DE ECONOMIA E SOCIOLOGIA RURAL, 44., 2006, Fortaleza. Anais... Brasília, DF: Sober, 2006. p. 52.

MARTIN, N. B. et al. Sistema integrado de custos agropecuários: Custagri. Informações Econômicas, São Paulo, v. 28, n. 1, p. 7-28, 1998.

MATSUNAGA, M. et al. Metodologia de custo de produção utilizada pelo IEA. Agricultura em São Paulo, São Paulo, v. 23, n. 1, p. 123-139, 1976.

OLIVEIRA, M. D. M. et al. Análise da eficiência energética e econômica dos sistemas de produção de milho safrinha no Médio Paranapanema, Estado de São Paulo. In: CONGRESSO BRASILEIRO DE ENGENHARIA AGRÍCOLA, 36., 2007, Bonito. Anais... Jaboticabal: SBEA, 2007. 1 CD-ROM.
RICHETTI, A. Estimativa de custo de produção de milho safrinha para 2007, em Mato Grosso do Sul e Mato Grosso. Dourados: Embrapa Agropecuária Oeste, 2007. (Comunicado técnico, 128).

SALLIT, F. A. A.; TOLEDO, P. E. N. Rentabilidade da safra de inverno na região de Assis: alternativas milho, soja e trigo. Informações Econômicas, São Paulo, v. 20, n. 7, p. 9-20, 1990.

SOUZA, M. C. M. et al. Custo de produção e receita líquida do milho safrinha na região do Médio Paranapanema, Estado de São Paulo, safra de 1993. Informações Econômicas, São Paulo, v. 23, n. 5, p. 25-37, 1993.

TSUNECHIRO, A. et al. Análise técnica e econômica de sistemas de produção de milho safrinha, região do Médio Paranapanema, Estado de São Paulo. Informações Econômicas, São Paulo, v. 36, n. 9, p. 62-70, 2006.

TSUNECHIRO, A.; FERREIRA, C. R. R. P. Contribuição da produtividade para o aumento da produção de milho no Brasil, 1993-2007. In: CONGRESSO NACIONAL DE MILHO E SORGO, 27., 2008, Londrina. Anais... Londrina: Embrapa Milho e Sorgo, 2008. 1 CD-ROM. 